\title{
Spontaneous regression of advanced transverse colon cancer with remaining lymph node metastasis
}

Bunpei Nishiura', Kensuke Kumamoto ${ }^{1 *}$, Shintaro Akamoto ${ }^{2}$, Eisuke Asano ${ }^{1}$, Yasuhisa Ando ${ }^{1}$, Hironobu Suto ${ }^{1}$ Takayoshi Kishino ${ }^{1}$, Minoru Oshima ${ }^{1}$, Masao Fujiwara ${ }^{3}$, Hisashi Usuki ${ }^{1}$, Keiichi Okano ${ }^{1}$ and Yasuyuki Suzuki ${ }^{1}$

\begin{abstract}
Background: The observation of spontaneous regression (SR) has been well documented for many cancer types, including renal cell carcinoma, non-Hodgkin's lymphoma, leukemia, neuroblastoma, and malignant melanoma. However, the SR frequency in colorectal cancer is very rare. Therefore, the accumulation of SR colorectal cancer cases might contribute to find the regression mechanism.
\end{abstract}

Case presentation: A 67-year-old woman received colonoscopy due to being positive for fecal occult blood testing and was diagnosed as having a transverse colon cancer at a local hospital. She was admitted to our institution for surgical treatment of the colon cancer. The colonoscopy revealed a type 2 tumor of $13 \mathrm{~mm}$ in diameter at the hepatic flexure of the transverse colon. The enhanced computed tomography (CT) showed an enlarged lymph node in the intermediate lymph node region. The 18F-fluorodeoxyglucose positron emission tomography/CT showed no abnormal accumulation on the transverse colon; however, an abnormal accumulation was found at the enlarged lymph node. The patient was preoperatively diagnosed as having advanced transverse colon cancer with lymph node metastasis and underwent laparoscopic right hemicolectomy with D3 lymph node dissection. Pathological examination showed only a scar-like tissue and no cancerous lesion in the transverse colon, while a metastatic lymph node was histologically confirmed in the intermediate lymph node region. Loss of MLH1 and PMS2 expression was observed in the cancer cells of both biopsy specimens and resected lymph nodes. No recurrence was seen for 5 years after surgery.

Conclusions: We reported a rare case of SR of the primary transverse colon cancer without regression of the metastatic regional lymph node. We considered that colorectal cancer with SR should be resected because even if SR of the primary lesion occurs, lymph node metastasis might have an inconsistent behavior as shown in the present case.

Keywords: Spontaneous regression, Advanced colon cancer

\footnotetext{
* Correspondence: kumamotk@med.kagawa-u.ac.jp

${ }^{1}$ Department of Gastroenterological Surgery, Faculty of Medicine, Kagawa

University, 1750-1 Ikenobe, Miki-cho, Kita-gun, Kagawa 761-0793, Japan

Full list of author information is available at the end of the article
}

\section{Springer Open}

(c) The Author(s). 2020 Open Access This article is licensed under a Creative Commons Attribution 4.0 International License, which permits use, sharing, adaptation, distribution and reproduction in any medium or format, as long as you give appropriate credit to the original author(s) and the source, provide a link to the Creative Commons licence, and indicate if changes were made. The images or other third party material in this article are included in the article's Creative Commons licence, unless indicated otherwise in a credit line to the material. If material is not included in the article's Creative Commons licence and your intended use is not permitted by statutory regulation or exceeds the permitted use, you will need to obtain permission directly from the copyright holder. To view a copy of this licence, visit http://creativecommons.org/licenses/by/4.0/. 


\section{Background}

The observation of spontaneous regression (SR) of cancer is mostly reported in renal cell carcinoma, nonHodgkin's lymphoma, leukemia, neuroblastoma, and malignant melanoma $[1,2]$. Among various cancers, the SR frequency in colorectal cancer is very rare. Although several regression mechanisms of cancer have been speculated [1, 2], it might be difficult to identify accurate mechanism depending on cases. The accumulation of SR colorectal cancer cases might contribute to find the regression mechanism. Recent reports [3-14] showed SR of primary lesions in colorectal cancer without lymph node metastasis. We herein report a rare case of SR of the primary transverse colon cancer without regression of the metastatic regional lymph node.

\section{Case presentation}

A 67-year-old woman received a medical checkup and found a positive fecal occult blood result. Her past medical history was appendicitis and mild pneumonitis. She was referred to a local hospital for further investigation, where colonoscopy revealed a cancer lesion in the transverse colon. Consequently, she was admitted to our institution for surgical treatment.

Physical examination showed no significant findings. Furthermore, the blood test showed no abnormal findings except for mild anemia ( $\mathrm{Hb} 12.9 \mathrm{~g} / \mathrm{dl}$ ). The values of tumor markers were within normal limits (CEA 0.6 ng/ml, CA19-9 $31 \mathrm{U} / \mathrm{ml})$.

Colonoscopy was preoperatively performed for the marking neat of the tumor using an ink injection method. The tumor revealed a type 2 lesion of $13 \mathrm{~mm}$ in diameter at the hepatic flexure of the transverse colon (Fig. 1a). The histological diagnosis of the biopsy was a poorly differentiated carcinoma with a signet-ring cell carcinoma component (Fig. 1b). Barium enema of the colon revealed a trapezoid-shaped lesion at the same location of the transverse colon (Fig. 2a), leading to the prediction of the wall invasion to MP or deeper. The enhanced computed tomography (CT) could not recognize a tumor in the transverse colon, but an enlarged node was detected in the intermediate lymph node region (Fig. 2b). There was no evidence of distant metastasis.The 18F-fluorodeoxyglucose positron emission tomography (PET)/CT showed an abnormal accumulation of SUVmax 3.8 only on the intermediate lymph node (Fig. 2c). No abnormal accumulation was detected in the transverse colon. Based on these preoperative examination results, she was diagnosed of an advanced transverse colon cancer with lymph node metastasis (T2, N1a, M0, cStageIIIA according to the UICC-TNM classification, 8th edition).

Laparoscopic right hemicolectomy with D3 lymph node dissection was performed 3 months later after the initial colonoscopy without any treatment, including folk medicine and medication for boost immunity. The enlarged lymph node was located nearby the left branch of the middle colic artery. Macroscopically, the tumor was not observed in the resected specimens (Fig. 3). A scarlike lesion around the preoperative inking was seen in the colonic mucosa (Fig. 3). Pathological findings revealed inflammatory cell infiltration and fibrosis between the submucosa (SM) and the muscularis propria (MP) (Fig. 4a). No malignant cells were identified at the scar lesion, although poorly differentiated carcinoma with mucinous component was pathologically observed in the harvested enlarged lymph node (Fig. 4b).

She was discharged from our institution 9 days after the operation without any complication and was given adjuvant chemotherapy due to regional lymph node metastasis. At 5 years after surgery, there is no evidence of local recurrence and distant metastasis.

\section{Discussion}

To the best of our knowledge, this is the first report of SR case of primary transverse colon cancer in which regional lymph node metastasis was present though there have been several reports of SR primary colorectal cancer without lymph node metastasis. SR has been well documented for many cancer types, including renal cell

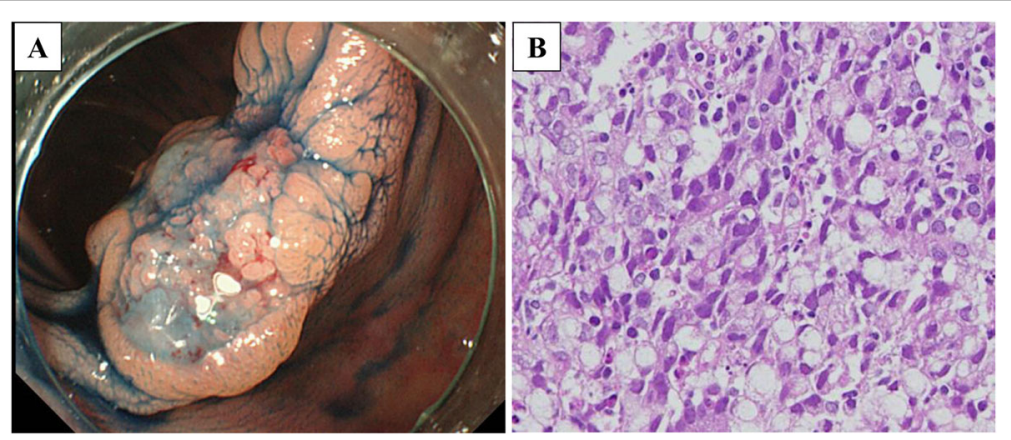

Fig. 1 a Colonoscopy revealed a type 2 tumor of $13 \mathrm{~mm}$ in diameter at the transverse colon. $\mathbf{b}$ The biopsy specimen showed a poorly differentiated adenocarcinoma 


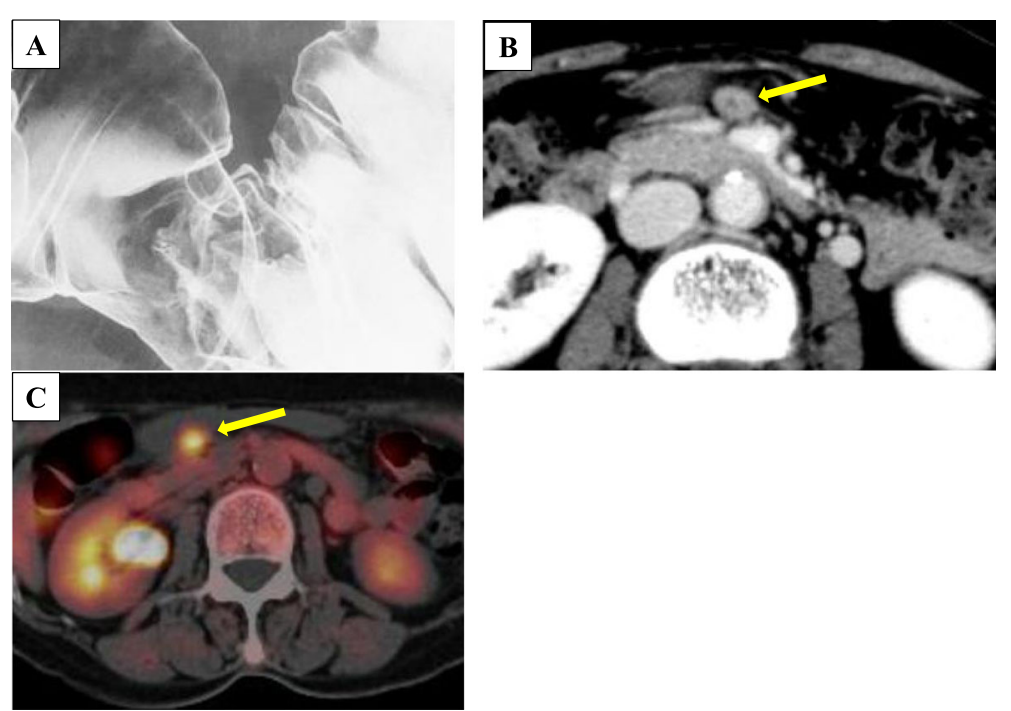

Fig.2 a Barium enema examination revealed a trapezoid-formed change at the hepatic flexure of the transverse colon. $\mathbf{b}$ Abdominal enhanced CT showed an enlarged intermediate lymph node (arrow). c PET/CT revealed an abnormal accumulation of SUVmax 3.8 on the intermediate lymph node (arrow).

carcinoma, non-Hodgkin's lymphoma, leukemia, neuroblastoma, and malignant melanoma [1, 2]. SR of colon cancer is very rare, accounting for less than $2 \%$ of such cases [1]. SR of neoplasms is defined as the malignant tumor mass partially or completely disappears without any treatment or as a result of a therapy considered inadequate to influence a systemic neoplastic disease [1, 2]. Abdelrazeq et al. [1] summarized SR cancers, which were reported from the 1900s through 2005, including 11 SR cases of primary colorectal cancer and 10 cases of metastatic lesions. Since almost cases were treated with non-curative operation for colorectal cancer, the residual tumor was expected to increase. However, these patients survived for a long time without any clinical evidence of malignancy. In this period, the diagnostic imaging, including colonoscopy and CT, was not sufficient and the autopsies were not performed to confirm the disappearance of cancer cells.

After the year 2000, 12 cases with SR of a primary colorectal cancer have been reported in Japan (Table 1). In the $13 \mathrm{SR}$ cases including the present case, the median age was 70 years old (range: $60-80$ years) and 4 cases were females. The primary sites of colorectal cancer were localized in the cecum $(n=1)$, ascending $(n=$ $3)$, transverse $(n=7)$, and rectum $(n=2)$. Based on these recent reports, the number of right hemi-colon cancer

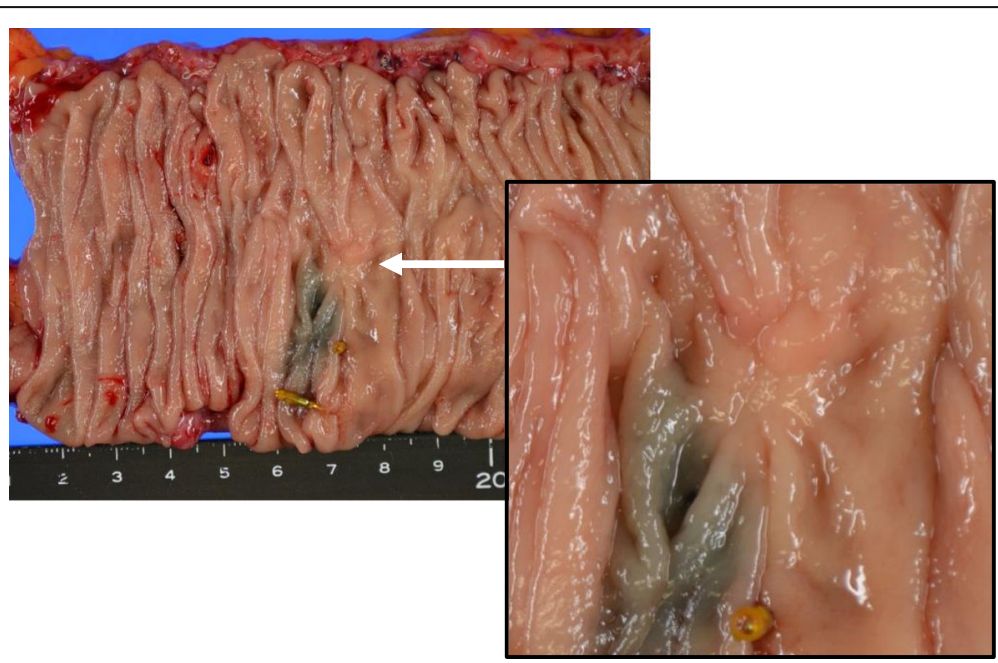

Fig. 3 The resected specimen showed only a scar near ink-injected site, but no tumor lesion was detected. Only a scar-like lesion was detected 


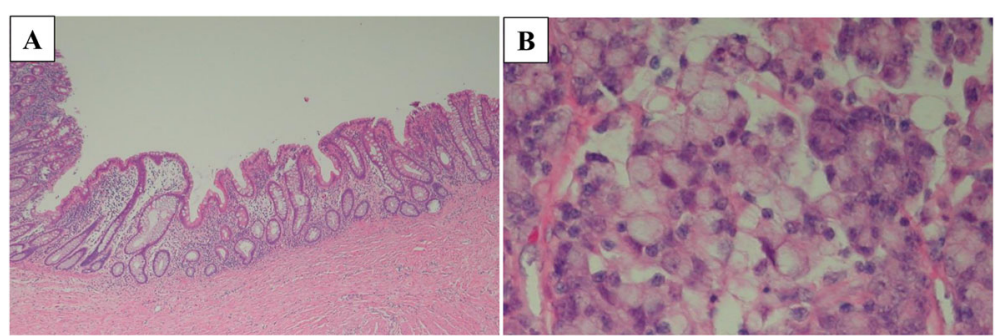

Fig.4 a There was inflammation and fibrosis with no cancer cells. b Metastatic lymph node was diagnosed as poorly differentiated carcinoma including mucinous component

$(n=11)$ was larger than that of left hemi-colon and rectal $(n=2)$ cancer. A previous report [1] showed opposite data that the number of left hemi-colon $(n=5)$ and rectal $(n=11)$ cancer was larger than that of right hemicolon cancer $(n=5)$. The histological types varied and were not particularly characteristic. The depth of the wall invasion was $6 \mathrm{SM}$ and 7 MP. Lymph node metastasis was not recognized except in the present case. The median duration of the disappearance of the tumor from initial examinations was 2 months, which ranged from 1 to 7 months. These results from the Japanese series after the year 2000 indicated that the SR of colorectal cancer might occur when the tumor is located at the right hemi-colon, the tumor size is up to $30 \mathrm{~mm}$, the wall depth is up to MP, and the operation waiting period is long, regardless of the histological type.

Although previous reports $[1,2]$ suggested that the causal factors of SR might include tumor destruction or necrosis by immunological mechanisms or physical stimulation, the exact trigger of SR has not been fully elucidated depending on the cases. Since the frequency of SR has been reported in renal cell carcinoma and malignant melanoma, which are considered to have many neoantigens, an antitumor immune response might be the most likely explanation for the mechanism of SR. As the number of right hemi-colon cancer was larger than that of left hemi-colon and rectal cancer in recent reported cases, we come up with the association of microsatellite instability (MSI). Among colorectal cancer patients, those with MSI-high have generally good prognosis when compared with those with microsatellite stable (MSS) [15]. It could be explained that MSI-high cancer produced many cancer-specific antigens, thereby acquiring the ability of immune response for cancer antigens. Therefore, we investigated the contribution of mismatch repair genes expression in the cancer tissue using an immunohistochemical staining method as described previously [16]. As a result, the loss of MLH1 and PMS2 expression was observed in both primary cancer (Fig. 5) and the metastatic lymph node, suggesting

Table 1 Reported cases of spontaneous regression of colorectal cancer in Japan

\begin{tabular}{|c|c|c|c|c|c|c|c|c|c|c|c|c|c|}
\hline & Author & $\begin{array}{l}\text { Reported } \\
\text { year }\end{array}$ & Age & Sex & $\begin{array}{l}\text { Primary } \\
\text { site }\end{array}$ & Types & $\begin{array}{l}\text { Size } \\
(\mathrm{mm})\end{array}$ & Histology & Depth & $\mathrm{pN}$ & Stage & $\begin{array}{l}\text { Duration } \\
\text { (month) }\end{array}$ & $\begin{array}{l}\text { Prognosis } \\
\text { (month) }\end{array}$ \\
\hline 1 & Kamesui et al. [3] & 2000 & 66 & $\mathrm{~F}$ & Ascending & $0-$ Isp & 20 & Moderately & SM & 0 & 1 & 2 & $12 \mathrm{NR}$ \\
\hline 2 & Sakamoto et al. [4] & 2009 & 80 & M & Rectum & 2 & 25 & Well & MP & 0 & 1 & 3 & $24 N R$ \\
\hline 3 & Shimizu et al. [5] & 2010 & 80 & M & Transverse & 2 & 25 & Moderately & MP & - & - & 7 & $64 N R$ \\
\hline 4 & Nakashima et al. [6] & 2012 & 76 & $\mathrm{~F}$ & Caecum & $0-1 p$ & 20 & Well & $\begin{array}{l}\text { SM } \\
\text { massive }\end{array}$ & 0 & 1 & 2 & $18 \mathrm{NR}$ \\
\hline 5 & Sekiguchi et al. [7] & 2013 & 69 & $\mathrm{~F}$ & Ascending & 0-Ila & 20 & Moderately & $\begin{array}{l}\text { SM } \\
\text { massive }\end{array}$ & 0 & 1 & 1.5 & - \\
\hline 6 & Nakamura [8] & 2013 & 60 & M & Rectum & $0-\|a+\| c$ & 10 & Well & SM & - & - & 1 & $18 \mathrm{NR}$ \\
\hline 7 & Serizawa et al. [9] & 2015 & 75 & M & Transverse & $0-\|c+\| l a$ & 15 & Well & SM & 0 & 1 & 2.5 & - \\
\hline 8 & Kihara et al. [10] & 2015 & 64 & M & Transverse & 2 & 30 & Moderately & MP & 0 & 1 & 1.5 & $12 N R$ \\
\hline 9 & Chida et al. [11] & 2017 & 80 & M & Transverse & 2 & 30 & Poorly & MP & 0 & 1 & 1 & $12 \mathrm{NR}$ \\
\hline 10 & Yoshida et al. [12] & 2018 & 73 & M & Transverse & $0-\|l a+\| c$ & 10 & Moderately & $\begin{array}{l}\text { SM } \\
\text { massive }\end{array}$ & 0 & 1 & 3 & 9NR \\
\hline 11 & Karakuchi et al. [13] & 2019 & 70 & M & Transverse & 2 & 30 & Poorly & MP & 0 & 1 & 2 & $11 \mathrm{NR}$ \\
\hline 12 & Kawakita et la [14]. & 2019 & 62 & M & Ascending & 2 & 10 & Poorly & MP & 0 & 1 & 1 & $6 \mathrm{NR}$ \\
\hline 13 & Our case & 2019 & 67 & $\mathrm{~F}$ & Transverse & 2 & 13 & Poorly & MP & $1 a$ & 3 & 3 & $60 \mathrm{NR}$ \\
\hline
\end{tabular}




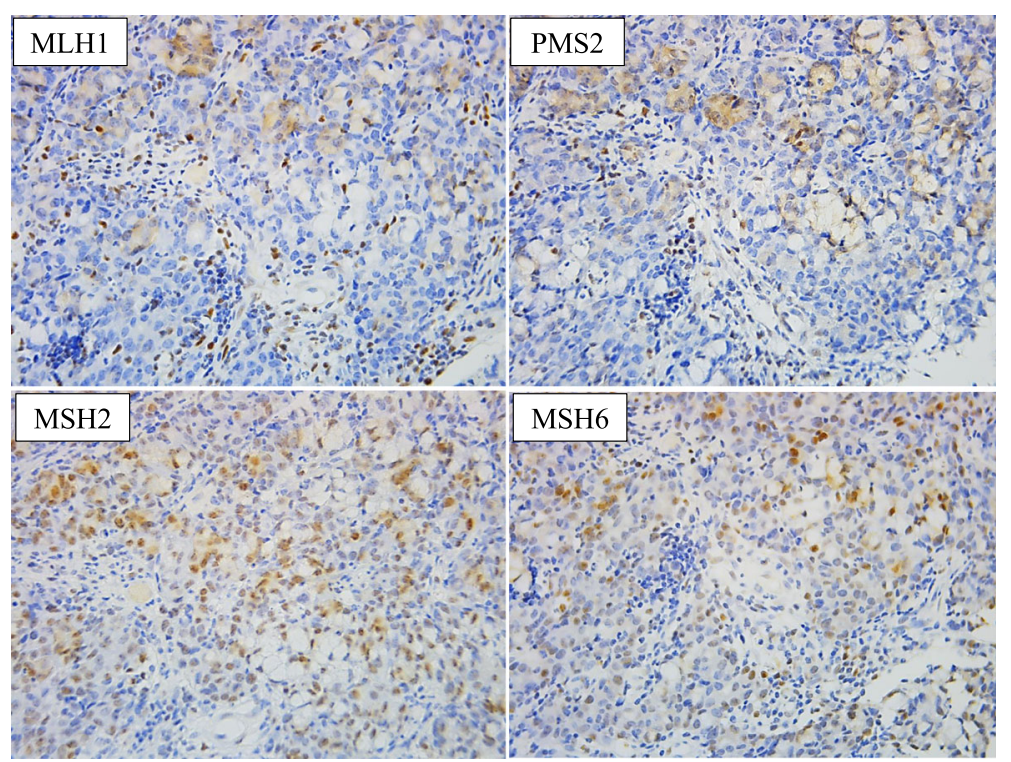

Fig. 5 Immunohistochemical staining of indicated mismatch repair proteins in the biopsy specimen from the primary cancer

that the abnormality of MLH1 could be affected. There were no past histories of colon cancer or endometrial cancer, and no family history of colorectal cancer, which were suspected in Lynch syndrome. Therefore, MLH1 might lose its function due to acquired predisposition. In our case, the primary lesion might disappear due to the immune response through cancer-specific antigens produced by the loss of MLH1 functions.

However, the primary lesion had SR while the regional metastatic lymph node neither disappeared nor reduced in size. Although observation time might have been insufficient in the present case, it is unlikely that only an antitumor immune response can explain this inconsistency in behavior between the primary and metastatic lesions. It has been reported that the gene expression profiles in metastatic cancer were different from those in primary cancer [17]. Therefore, the immune response could be different between the primary and metastatic cancer, though the MLH1 loss was detected in both the primary cancer and the metastatic lymph node.

It has been reported that SM invasive tumors might disappear by some kind of physical stimulation such as excessive movement due to mechanical cleansing for examinations or the effect of medical examinations, including colonoscopy with biopsy and barium enema [18]. A recent report [18] suggested that the vasoconstriction effect by the epinephrine injection under the SM tumor for endoscopic submucosal dissection could induce SR due to tumor necrosis. Meanwhile, MP invasive colon cancers such as the present case can disappear by physical stimulation remains unclear.

\section{Conclusion}

SR of colorectal cancer is very rare. Therefore, the occasion and treatment strategies have not been established. We considered that colorectal cancer with SR should be resected because even if SR of the primary lesion occurs, lymph node metastasis might have an inconsistent behavior as shown in the present case.

\section{Abbreviations \\ CT: Computed tomography; MP: Muscularis propria; PET: 18F- \\ Fluorodeoxyglucose positron emission tomography; SM: Submucosa}

\section{Acknowledgements}

Not applicable.

\section{Authors' contributions}

$\mathrm{BN}, \mathrm{SA}$, and EA performed the operation. BN, SA, EA, TK, YA, HS, MO, MF, and $\mathrm{HU}$ managed the perioperative course. KK performed the immunohistochemical staining. BN wrote the manuscript. SA and KK supported in the writing of the manuscript. KO and YS supervised the writing of the manuscript. The authors read and approved the final manuscript.

\section{Funding}

None of the authors have anything to disclose.

\section{Availability of data and materials}

The authors declare that all the data in this article are available within the article.

\section{Ethics approval and consent to participate}

The present study was conducted in accordance with the ethical standards of our institution.

\section{Consent for publication}

Informed consent for publication of the patient's clinical details and clinical images was obtained from the patient. 


\section{Competing interests}

The authors declare that they have no competing interests.

\section{Author details}

'Department of Gastroenterological Surgery, Faculty of Medicine, Kagawa University, 1750-1 Ikenobe, Miki-cho, Kita-gun, Kagawa 761-0793, Japan.

${ }^{2}$ Department of Surgery, Sumitomo Besshi Hospital, Niihama, Japan.

${ }^{3}$ Department of Surgery, Takamatsu Red Cross Hospital, Takamatsu, Japan.

Received: 26 February 2020 Accepted: 28 April 2020

Published online: 11 May 2020

\section{References}

1. Abdelrazeq AS. Spontaneous regression of colorectal cancer; a review of cases from 1900 to 2005. Int J Color Dis. 2007;22:727-36.

2. Papac RJ. Spontaneous regression of cancer. Cancer Treat Rev. 1996;22(6): 395-423.

3. Kamesui T, Munemoto Y, Fujisawa K, Kasahara Y, Mitsui T, Asada Y, lida Y, Miura S, Fujisawa M, Tsukioka N. A case of spontaneous dislodging of early colon cancer. Gastroenterol Endosc. 2000;42:1218-22.

4. Sakamoto S, Fu K, Kobayashi O, Matsuyama S, Miyazaki A, Ogura K, Watanabe S. Spontaneous complete regression of a rectal cancer. Endoscopy. 2009;41:910-2.

5. Shimizu H, Kochi M, Kaiga T, Mihara Y, Fujii M, Takayama T. A case of spontaneous regression of advanced colon cancer. Anticancer Res. 2010;30: 2351-4.

6. Nakashima M, Hori K, Kimura Y, Hayashi K, Yokomizo H, Hirata T. A case of spontaneous regression of colon cancer. Nihon Rinsyo Geka Gakkai Zasshi. 2012;73:1482-5.

7. Sekiguchi M, Ito K, Matsuhashi N. Spontaneously disappearing colon cancer. Dig Endosc. 2013;25:88-9.

8. Nakamura F, Sakamoto T, Nakajima T, Saito Y, Taniguchi H, Matsuda T. A case of rectal tumor in which the shape altered with regression in short period. BMC Gastroenterol. 2013;13:146.

9. Serizawa M, Nakayama J, Kawarabayashi N. A case of spontaneous regression of transverse colon cancer. Gastroenterol Endosc. 2015;57:1490-5.

10. Kihara K, Fujita S, Ohshiro T, Yamamoto S, Sekine S. Spontaneous regression of colon cancer. Jpn J Clin Oncol. 2015;45:111-4.

11. Chida K, Nakanishi K, Shomura H, et al. Spontaneous regression of transverse colon cancer: a case report. Surgical Case Reports. 2017;3:65.

12. Yoshida K, Sawaya M, Mikami T, et al. A case of transverse colon cancer that underwent spontaneous regression after biopsy. Gastroenterol Endosc. 2018;60:2303-9.

13. Karakuchi N, Shimomura M, Toyota K, Hinoi T, Yamamoto H, Sadamoto S, Mandai K, Egi H, Ohdan H, Takahashi T. Spontaneous regression of transverse colon cancer with high-frequency microsatellite instability: a case report and literature review. World J Surg Oncol. 2019 Jan 15;17(1):19.

14. Kawakita I, Takeda K, Tanaka Y, et al. Spontaneous regression of ascending colon cancer. Jpn J Gastroenterol Surg. 2019;52:106-11.

15. Benatti P, Gafà R, Barana D, Marino M, Scarselli A, Pedroni M, Maestri I, Guerzoni L, Roncucci L, Menigatti M, Roncari B, Maffei S, Rossi G, Ponti G, Santini A, Losi L, Di Gregorio C, Oliani C, Ponz de Leon M, Lanza G. Microsatellite instability and colorectal cancer prognosis. Clin Cancer Res. 2005;11(23):8332-40.

16. Suzuki O, Eguchi H, Chika N, Sakimoto T, Ishibashi K, Kumamoto K, Tamaru J, Tachikawa T, Akagi K, Arai T, Okazaki Y, Ishida H. Prevalence and clinicopathologic/molecular characteristics of mismatch repair-deficient colorectal cancer in the under-50-year-old Japanese population. Surg Today. 2017 Sep;47(9):1135-46.

17. Koh KH, Rhee H, Kang HJ, Yang E, You KT, Lee H, Min BS, Kim NK, Nam SW, Kim H. Differential gene expression profiles of metastases in paired primary and metastatic colorectal carcinomas. Oncology. 2008;75(1-2):92-101.

18. Tanaka F, Hiraki M, Yamada K, et al. A case of spontaneous regression of sigmoid colon cancer after local injection for non-lifting sign evaluation. Nihon Rinsyo Geka Gakkai Zasshi. 2019;80:368-72.

\section{Publisher's Note}

Springer Nature remains neutral with regard to jurisdictional claims in published maps and institutional affiliations.

\section{Submit your manuscript to a SpringerOpen ${ }^{\odot}$ journal and benefit from:}

- Convenient online submission

- Rigorous peer review

- Open access: articles freely available online

- High visibility within the field

- Retaining the copyright to your article

Submit your next manuscript at $\boldsymbol{\nabla}$ springeropen.com 